\title{
Formação de professores da Educação Infantil para o uso de recursos digitais em tempos de pandemia
}

\author{
José Ricardo C. Costa ${ }^{1}$, Hanna Almeida Souza ${ }^{2}$, Maria Auricélia da Silva ${ }^{3}$ \\ ${ }^{1}$ Zootecnia - Universidade Federal do Ceará (UFC) - Campus do Pici - Bloco \\ 808 - Fortaleza-CE - Brasil \\ ${ }^{2}$ Geografia - Universidade Federal do Ceará (UFC) - Campus do Pici - Bloco 911- \\ Fortaleza-CE - Brasil \\ ${ }^{3}$ Unidade Universitária Federal de Educação Infantil Núcleo de Desenvolvimento da \\ Criança - Universidade Federal do Ceará (UFC) - Campus do Pici - Bloco 859 - \\ Fortaleza-CE - Brasil \\ cassimiroricardodalu.ufc.br, hannaalso04 g gmail.com, \\ auricelia.silva@ufc.br
}

\begin{abstract}
The gaps in relation to the use of digital technologies in education have become more evident with the SARS-CoV-2 pandemic. The general objective of this work: to offer training to Kindergarten teachers for the use of digital resources. Specific objectives: to probe the main challenges of early childhood education teachers for remote work in the context of the pandemic; offer workshops for the appropriation of technological resources suitable for remote work in Early Childhood Education. The methodology included surveying the needs of teachers and offering technological workshops. The results showed that the teachers need training that is adequate to the specificities of Early Childhood Education.
\end{abstract}

Resumo. As lacunas em relação ao uso de tecnologias digitais na educação tornaram-se mais evidentes com a pandemia do SARS-CoV-2. Objetivo geral deste trabalho: oferecer formação a professoras de Educação Infantil para o uso de recursos digitais. Objetivos especificos: sondar os principais desafios de professoras da Educação Infantil para o trabalho remoto no contexto da pandemia; oferecer oficinas para apropriação de recursos tecnológicos adequados ao trabalho remoto na Educação Infantil. A metodologia contemplou a sondagem das necessidades docentes e a oferta de oficinas tecnológicas. Os resultados mostraram que as professoras necessitam de uma formação adequada às especificidades da Educação Infantil.

\section{Introdução}

As tecnologias datam de um período tão antigo quanto a própria humanidade e, cada vez mais, são aperfeiçoadas e presentes em nosso cotidiano. As Tecnologias Digitais de Informação e Comunicação (TDIC) compõem um conjunto de recursos que permitem a interatividade e ampliam as possibilidades de aprendizagem. Com suas convergências e sinergias em relação às mais variadas mídias, as TDIC impõem mudanças radicais nas formas de acesso à informação, à cultura e ao entretenimento, influenciando a constituição de conhecimentos, valores e atitudes [Kenski 2007]. A integração dessas 
tecnologias com a Educação Infantil pode promover ensino e aprendizagem.

"O professor do século XXI possui um leque diversificado de opções metodológicas e possibilidades de mediar o conhecimento dos seus alunos a partir da inserção das tecnologias em suas práticas pedagógicas" [Santos e Teixeira 2019, p. 836]. Nessa perspectiva, a formação continuada para professores pode promover ações teóricopráticas com vistas ao desenvolvimento de habilidades e competências para o uso das tecnologias digitais, utilizadas como instrumento pedagógico que possa auxiliar nos processos de ensino e aprendizagem.

Com a pandemia do SARS-CoV-2, que acometeu o mundo entre os anos $2020 \mathrm{e}$ 2021, tornou-se essencial fazermos uso das tecnologias na educação, pois elas se mostraram a opção mais viável para a promoção da aprendizagem em processos pedagógicos remotos.

Em março de 2020, começaram a ser identificados os primeiros casos de COVID 19 e não demorou para as atividades letivas presenciais serem suspensas, sendo retomadas posteriormente, por meio remoto. Esse período de pausa serviria para os professores se adequarem às metodologias adequadas ao novo contexto, inteiramente on-line. Porém, para aqueles que tinham pouco contato com as tecnologias digitais, um curto período não supriria todas as demandas.

Essa necessidade de adaptação rápida exige cuidados, sobretudo quando envolve a Educação Infantil, já que a virtualização das experiências de aprendizagem adaptada ao formato remoto não é capaz de substituir os resultados da atividade presencial, que envolve as interações e brincadeiras, eixos fundantes do trabalho pedagógico na Educação Infantil, conforme as Diretrizes Curriculares Nacionais para a Educação Infantil - DCNEI [Brasil 2010].

A partir dessas questões e inquietações, foi elaborado o problema desta pesquisa, que consistiu em conhecer as estratégias e os desafios que professoras da Educação Infantil estavam vivenciando para trabalhar de forma remota com as crianças.

As premissas elaboradas consideravam as seguintes ideias: as professoras da Educação Infantil estavam buscando a apropriação do suporte tecnológico, pois as demandas do momento exigiam essa tomada de atitude; era necessário buscar recursos tecnológicos adequados ao trabalho com a Educação Infantil, estudar e experimentar as possibilidades dos recursos escolhidos; os momentos formativos deveriam atender às professoras de forma cuidadosa, com espaços para dúvidas, sugestões e compartilhamento de experiências, possibilitando um momento colaborativo.

A partir dessas hipóteses e da sondagem das principais necessidades formativas de um grupo de professoras de uma instituição pública de Educação Infantil, as ações formativas ocorreram remotamente, em formato de oficinas, favorecendo a aprendizagem colaborativa.

Todo esse processo é apresentado neste trabalho, organizado na seguinte sequência de seções: introdução, quadro teórico, percurso metodológico, resultados e discussão e considerações finais. A seguir, será apresentado o quadro teórico que contribuiu para o embasamento do trabalho.

\section{Quadro Teórico}

A formação inicial não atende completamente às necessidades dos profissionais da educação, como acontece nas demais profissões. Por isso, é fundamental dar continuidade 
ao processo formativo, sobretudo no mundo globalizado e multicultural em constante mudança, já que um dos pressupostos presentes nos Referenciais para Formação de Professores [Brasil 2002, p. 18] considera que o "desenvolvimento profissional permanente é necessidade intrínseca à sua atuação e, por isso, um direito de todos os professores".

Para atender às recomendações das DCNEI [Brasil 2010] e da Base Nacional Comum Curricular - BNCC [Brasil 2018], que preconizam a utilização das TDIC como forma de possibilitar a diversificação das experiências infantis, por meio do uso de diversas ferramentas tecnológicas, os professores precisam, cada vez mais, estar preparados para o mundo em transformação. De acordo com a BNCC [Brasil 2018, p. 9], é importante

compreender, utilizar e criar tecnologias digitais de informação e comunicação de forma crítica, significativa, reflexiva e ética nas diversas práticas docentes, como recurso pedagógico e como ferramenta de formação, para comunicar, acessar e disseminar informações, produzir conhecimentos, resolver problemas e potencializar as aprendizagens.

Santos e Teixeira (2019) destacam a competência da Fluência Tecnológica Digital para os professores atuantes no século XXI, a fim de que sejam capazes de mediar os conhecimentos a partir de análises, planejamentos, organização de materiais e avaliações envolvendo opções tecnológicas, a fim de potencializar os processos de ensino e aprendizagem, abrangendo os diferentes perfis de alunos. Para que isso seja possível, Hitzschky et al $(2018 ; 2020)$ reiteram a importância de uma sólida formação inicial e continuada de professores.

Ao discutirem os processos formativos, Costa e Lopes (2016) advertem que a formação docente é algo bem mais complexo do que apenas cursos e encontros de capacitação, pois a formação continuada deve ser pensada e elaborada tendo o professor como protagonista, com foco em suas necessidades, interesses e especificidades do trabalho que realiza.

Para a realização deste trabalho, elegemos a perspectiva de formação em que os professores sejam protagonistas do seu processo de apropriação tecnológica, participem da elaboração da proposta de modo a garantir que a formação contemple as necessidades e interesses de determinado grupo de professores, preferencialmente em seu local de trabalho, de forma continuada e em serviço.

Nessa perspectiva, buscamos esteio em pesquisas para o uso de recursos tecnológicos na Educação Infantil, especialmente nos anais de eventos como o Congresso sobre Tecnologias na Educação (CTRL + E), o Workshop de Informática na Escola (WIE) realizado como subevento do Congresso Brasileiro de Informática na Educação (CBIE) e a Revista Brasileira de Informática na Educação (RBIE), no período de 2016 a 2020.

Dada a escassez de trabalhos desenvolvidos sobre a formação de professores da Educação Infantil para o uso de recursos digitais, destacamos pesquisas que abordam essa temática em outros níveis da Educação Básica, cujas formações para docentes alinhamse à perspectiva que desenvolvemos neste trabalho.

Hitzschky et al (2018) relatam um trabalho realizado em uma escola pública do Ceará sobre formação de professores dos anos finais do Ensino Fundamental voltada à apropriação de Recursos Educacionais Digitais (RED). Os autores ressaltam que apenas a exposição dos recursos não é efetiva, sendo necessária uma intervenção que favoreça a relação entre teoria e prática acerca dos recursos em estudo. Esses pesquisadores obtiveram resultados positivos, pois, ao final da formação, os professores demonstraram 
conhecimento sobre seleção de RED, elaboraram planos de aula e/ou sequências didáticas e apresentaram dificuldades somente quanto ao uso de laptops.

Hitzschky et al (2020) apresentaram uma proposta semelhante em seu artigo sobre formação de professores da Educação Básica para seleção e análise de aplicativos educacionais, realizada como uma ação do Projeto de Extensão "Aprendizagem móvel e colaborativa no Ensino Fundamental", desenvolvido pelo Grupo de Pesquisa e Produção de Ambientes Interativos e Objetos de Aprendizagem (PROATIVA), da Universidade Federal do Ceará. Essa formação foi realizada para dez (10) professores, organizada em fases: apresentação, demonstração, seleção e análise de recursos digitais. Hitzschky et al (2020) concluíram que essa formação, bem como as experiências em sala de aula, ofereceram a possibilidade de construção de novos saberes e ajudaram na compreensão de processos pedagógicos que utilizam recursos digitais como suporte.

No trabalho de Dias et al (2020), uma equipe de professores e bolsistas planejou uma formação para os professores do Ensino Médio da Escola de Aplicação da Universidade Federal do Pará/EAUFPA e Escolas Estaduais do entorno da Universidade. Contudo, a pandemia da COVID-19 impôs obstáculos, acelerando a formação para atender ao caráter emergencial das demandas e possibilidades próprias daquele contexto. Dessa forma, o trabalho foi completamente realizado de maneira on-line e contemplou as ferramentas Google Classroom, Meet Hangout, Google Drive e Google Formulários, objetivando apresentar esses recursos, favorecer a realização do planejamento de atividades com recursos digitais e criar um e-book com os planejamentos elaborados pelos professores. Os autores concluíram que há muitas lacunas da formação inicial a serem superadas e deve existir uma formação continuada, relacionada ao uso pedagógico das TDIC, de forma a integrar essas tecnologias às atividades pedagógicas diárias.

Em se tratando da Educação Infantil ( 0 a 5 anos e 11 meses), os desafios impostos pela pandemia foram bem mais complexos, considerando que as interações e brincadeiras constituem os eixos norteadores do trabalho pedagógico, conforme recomendam as DCNEI [Brasil 2010]. Mesmo assim, foi necessário pensar sobre a possibilidade de encontros remotos para essa faixa etária e, diante dessa realidade, o Conselho Nacional de Educação (CNE), no Artigo 17 da Resolução No 2, de 10/12/2020 (Brasil, 2020), reforçou a necessidade e a importância do uso das tecnologias digitais para dar continuidade às práticas pedagógicas na Educação Infantil.

Este trabalho foi realizado no contexto da pandemia, considerando os desafios e demandas de professoras de uma instituição pública de Educação Infantil, mediante a perspectiva de mediarem encontros remotos com as turmas de crianças e, de forma emergencial, se apropriarem dos recursos digitais que thes oferecessem o suporte necessário.

\section{Percurso metodológico}

Esta experiência formativa foi desenvolvida com um grupo de cinco (5) professoras da Unidade Universitária Federal de Educação Infantil Núcleo de Desenvolvimento da Criança (UUNDC), que atende crianças de três a cinco anos de idade, na Universidade Federal do Ceará (UFC). O percurso formativo foi desenvolvido por meio de oficinas online, no período de agosto a novembro de 2020, utilizando a plataforma de videochamadas Google Meet.

O formato de oficinas foi escolhido pelo grupo de formadores (uma professora e três bolsistas) para que as professoras da UUNDC/UFC pudessem executar, em seu 
computador, as orientações necessárias ao funcionamento de cada ferramenta, demonstradas pelos mediadores. Ao mesmo tempo, as dúvidas que surgissem seriam sanadas imediatamente, à medida que as professoras iam aprendendo a usar as ferramentas.

A escolha das TDIC considerou alguns fatores, como: facilidade de uso; gratuidade; idioma em língua portuguesa; possibilidade de uso direto com crianças da Educação Infantil; suporte ao planejamento e à comunicação da comunidade escolar. Além disso, optamos por dialogar com as professoras, a fim de sondar suas necessidades e interesses, mas também apresentamos algumas sugestões.

Diante disso, as professoras sugeriram iniciar pelo Google Meet, ferramenta já conhecida por elas, que seria utilizada nos encontros remotos com as crianças. As docentes conheciam esse recurso, pois utilizavam em reuniões com o grupo de professoras, mas necessitavam explorar suas possibilidades, a fim de se sentirem seguras durante a realização de encontros on-line com as crianças.

Outra ferramenta solicitada pelas professoras foi o Google Drive, pois precisavam utilizá-lo para compartilhar e arquivar documentos em nuvem, como o planejamento das atividades e os registros do trabalho com as crianças (textos, fotografias, vídeos e gravações dos encontros on-line).

Dessa forma, já haviam sido listadas duas oficinas: Google Meet e Google Drive. Então, a equipe de formação sugeriu a exploração das ferramentas Jamboard e Google Desenhos, que permitem a representação livre, a criatividade e a autoria das crianças, além do compartilhamento do mesmo espaço de criação pelo grupo de crianças e a professora. O grupo de docentes mostrou-se interessado e, como o Jamboard e o Google Desenhos apresentam características semelhantes, ficou combinado que as duas seriam exploradas em uma mesma oficina.

As oficinas tiveram início em 31/08 e se prolongaram até 09/11/2020, quinzenalmente, de acordo com o cronograma estabelecido pela instituição. A cada oficina, uma nova ferramenta era apresentada, na seguinte sequência: Google Meet; Google Drive; Jamboard e Google Desenhos (ambas na mesma oficina). A duração das oficinas variava entre duas horas e duas horas e meia, conforme as demandas do grupo de professoras.

À medida que as oficinas aconteciam, uma professora solicitou ajuda para organizar as produções das crianças em um só lugar, pois eram diversas e em grande quantidade. A partir dessa solicitação, a equipe de formação sugeriu o Google Sites, já que as docentes estavam familiarizadas com o acesso ao Google, e a instituição oferece e-mail institucional, espaço ilimitado em nuvem e acesso a diversas ferramentas do Google.

Outra professora sugeriu a oficina Google Formulários, recurso que elas já conheciam, mas ainda não haviam utilizado para elaborar e compartilhar seus próprios questionários. Assim, foram acrescentadas mais duas oficinas, Google Sites e Google Forms, com a aprovação total do grupo de professoras.

Todas as oficinas foram ministradas pelo Google Meet e mediadas por dois bolsistas, sob a supervisão da orientadora deste trabalho. Ao final de cada oficina, era compartilhado um formulário que funcionava como um feedback para o aprimoramento das oficinas subsequentes e instrumento de coleta de dados dessa experiência.

A seguir, serão apresentados os resultados do desenvolvimento deste trabalho. 


\section{Resultados e Discussões}

A coleta de dados aconteceu por meio de questionários elaborados no Google Forms, em dois momentos: o primeiro questionário, de mesmo teor para todas as oficinas, era respondido pelas professoras imediatamente ao final de cada uma delas; o segundo formulário foi submetido às professoras sete meses após a última oficina, isto é, ao final do primeiro semestre letivo de 2021, para que elas tivessem tempo de utilizar as ferramentas trabalhadas durante as oficinas desenvolvidas em 2020, caso fossem interessantes e/ou necessárias para sua prática pedagógica.

O formulário disponibilizado após as oficinas tinha como objetivo o feedback imediato com vistas ao aperfeiçoamento das oficinas subsequentes acerca dos seguintes aspectos: se as professoras já conheciam e/ou haviam utilizado as ferramentas anteriormente; sobre a utilidade e possibilidades de uso das ferramentas para o trabalho pedagógico na Educação Infantil; em relação à metodologia empregada e à mediação realizada pelos formadores. Além disso, havia duas questões abertas, a fim de que as professoras apresentassem sugestões para o aperfeiçoamento das futuras oficinas e outros recursos digitais de seu interesse.

Em relação à oficina sobre Google Meet, as cinco professoras conheciam a ferramenta, a despeito de precisarem explorar mais esse recurso para se sentirem seguras quanto ao uso. Elas o avaliaram como "muito útil à prática pedagógica com crianças da UUNDC/UFC atualmente". Uma das professoras informou que já conhecia o Google Meet, mas a oficina "agregou novos conhecimentos ao observar o funcionamento com calma. O formato pra ver os participantes e outras funcionalidades". Outra professora citou algumas funcionalidades que ela ainda não conhecia, como "o agendamento prévio da reunião; o título prévio da reunião: a apresentação em uma janela; a gravação; o enquadramento de mais pessoas na tela". Sobre a metodologia, todas as docentes a avaliaram como "clara, didática e favoreceu a aprendizagem".

Quanto à oficina sobre Google Drive, as professoras conheciam superficialmente o recurso, mas ainda não tinham feito uso dele. As professoras consideraram o Google Drive "muito útil à prática pedagógica com crianças da UUNDC/UFC atualmente" e uma delas informou que "pode ser útil para diversas ações docentes". Elas citaram as possibilidades de utilização do Google Drive: "não sabia como editar documentos compartilhados"; "edição de documentos compartilhados"; "a possibilidade de arquivar"; "na escrita de documentos de forma colaborativa". Todas informaram que a metodologia da oficina foi "clara, didática e favoreceu a aprendizagem".

Na oficina sobre Jamboard e Google Desenhos, as professoras mostraram-se muito interessadas em aprender a usá-las, pois nenhuma delas conhecia esses recursos e os analisaram como "muito úteis à prática pedagógica com crianças da UUNDC/UFC atualmente". Uma das professoras assim se expressou sobre as ferramentas ainda desconhecidas: "novidade total". Outras duas professoras comentaram: só precisamos do 'tempo' em casa mesmo para praticar e estarmos aptas a usar com as crianças se for o caso; "adorei acessar ferramentas que as crianças também poderão interagir! Maravilhosa essa oficina!". Sobre a metodologia, todas a consideraram "clara, didática e favoreceu a aprendizagem".

Quanto à oficina sobre Google Sites, nenhuma das professoras tinha conhecimento sobre sua existência, e todas a avaliaram como "muito útil à prática pedagógica com crianças da UUNDC/UFC atualmente". Duas professoras assim se manifestaram: "é totalmente novo, mas já usei o blogger, há muito tempo, o que dá uma ideia de configurar"; "planejamento, vídeos e imagens e acessar outros links". A 
metodologia foi considerada "clara, didática e favoreceu a aprendizagem" por todas as professoras.

No tocante à oficina sobre Google Forms, duas professoras já haviam utilizado, mas com adultos. Todas julgaram a oficina "muito útil à prática pedagógica com crianças da UUNDC/UFC atualmente", e a metodologia foi considerada "clara, didática e favoreceu a aprendizagem". Duas professoras comentaram o que mais lhes havia chamado a atenção: "o acréscimo de vídeo e imagens e a barra de progresso"; "a possibilidade de inserir imagens, vídeos e QRcode". Sobre as possibilidades de utilização em sua prática pedagógica, as professoras citaram: "para comunicação com as famílias, para possíveis votações com as crianças, por exemplo a história que será lida no encontro on-line"; "depois da oficina, até mesmo o uso com as crianças eu estou achando que é possível"; "em ações de pesquisa e extensão"; "em atividades com as crianças".

A avaliação das oficinas e os comentários das professoras indicam que a formação foi satisfatória, sendo a maioria dos recursos tecnológicos desconhecidos ou pouco familiares para elas. Em alguns comentários, podemos perceber que houve a compreensão sobre o funcionamento das ferramentas, mas o processo de apropriação tecnológica requer tempo e prática para que a facilidade de uso se consolide.

$\mathrm{O}$ fato de as professoras listarem suas demandas favoreceu o processo formativo, aspectos observados por meio do engajamento e interesse demonstrado por elas durante as oficinas. Essas constatações corroboram a importância de o professor participar do planejamento de suas formações, evidenciando necessidades, interesses e alinhamento da proposta com sua prática pedagógica.

O segundo formulário, enviado às professoras sete meses após a última oficina, tinha como objetivo saber se, durante esse período, as professoras haviam desenvolvido atividades com as crianças utilizando as ferramentas apresentadas durante as oficinas oferecidas ao longo do segundo semestre de 2020. As respostas foram solicitadas em uma escala de 0 a 5, variando em relação ao nível de utilização das ferramentas, isto é, do menor ao maior uso, e organizadas em forma de gráfico:

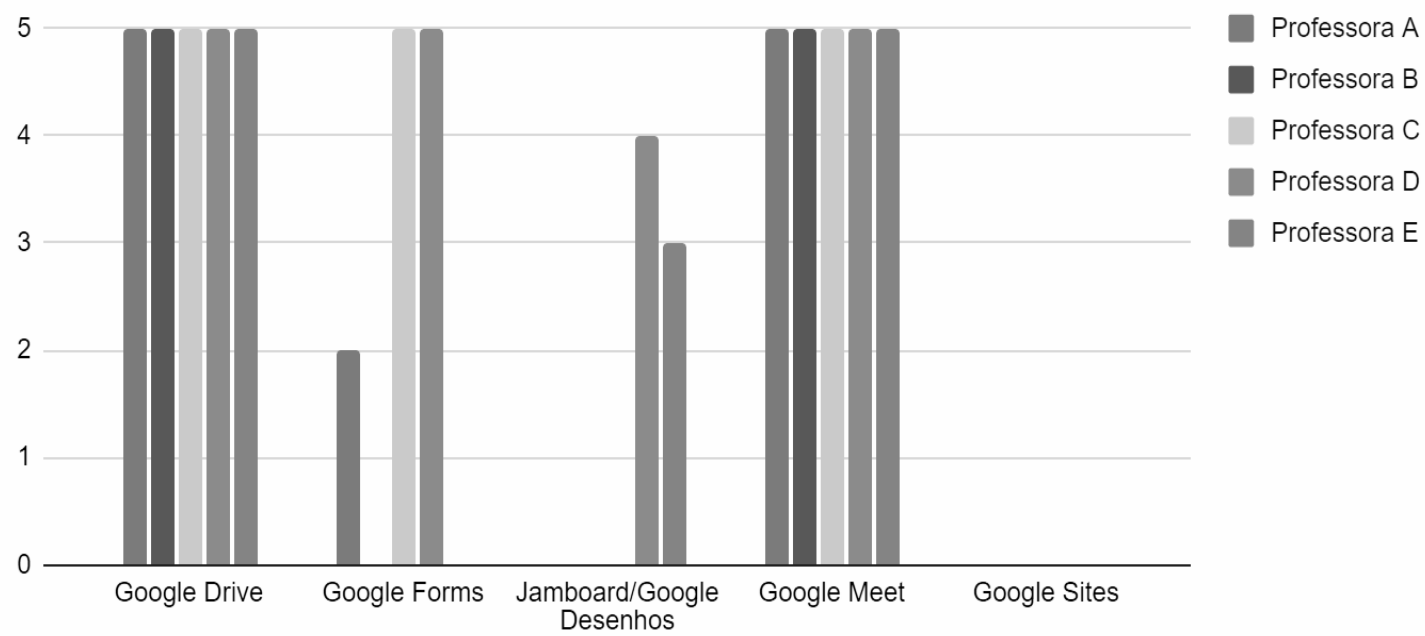

Figura 1. Escala de avaliação da utilização das tecnologias apresentadas nas oficinas

O gráfico permite-nos observar que as ferramentas Google Drive e Google Meet foram utilizadas por todas as professoras, de forma sistemática, e todas elas as utilizaram 
frequentemente, isto é, no nível 5 da escala.

O Google Drive foi usado nas seguintes situações: "para arquivar os materiais de registros das crianças"; "todos os registros, planejamentos, imagens e transcrições dos encontros estão sendo organizados no Google Drive"; "para arquivar arquivos com segurança e organizá-los em pastas acessíveis no grupo das professoras e no Drive individual também. Tive mais clareza desse uso e desfiz o 'bloqueio' de utilizá-lo"; "para armazenar arquivos de trabalho importantes"; "na produção de textos e documentos".

As professoras informaram como haviam utilizado o Google Meet: "encontro com as crianças, reuniões com as famílias e reunião com bolsistas"; "é a plataforma na qual os encontros com as crianças acontecem"; "foi usada constantemente, como o recurso principal, e mais conhecido pelas famílias". Foi e está sendo utilizado para a realização dos encontros on-line com as crianças. No caso, projetamos histórias em pdf ou imagens"; "como recurso para realização de encontros on-line com as crianças".

O Google Forms foi muito bem utilizado pelas Professoras C e D e, razoavelmente, usado pela Professora A, mas não foi usado por outras duas professoras. Essas foram as formas de utilização do Google Forms: "quando necessário, já criei formulários voltados para os bolsistas, a fim de obter feedback deles de estudo teórico e impressões acerca do trabalho"; "respondendo a formulários enviados".

A despeito de o Jamboard e o Google Desenhos haverem empolgado muito as professoras durante a oficina, apenas as Professoras D e E os utilizaram, sendo que uma delas fez um bom uso, e a outra usou com menor intensidade. As docentes que utilizaram esses recursos informaram como os utilizaram: "foi utilizada com as crianças do grupo Infantil 5. Elas exploraram a ferramenta para desenhar"; "oportunizando interações com as crianças, mas sempre com a mediação de um adulto. A própria criança não consegue manusear a Jamboard e acompanhar o encontro on-line ao mesmo tempo".

O Google Sites não foi utilizado por nenhuma das professoras, mesmo tendo sido considerada uma ferramenta muito adequada ao trabalho pedagógico na Educação Infantil como um ambiente capaz de reunir as produções das crianças em um só lugar e possibilitar interação. Uma delas justificou: "Infelizmente não arrisquei por medo de não dar conta do trabalho".

Pedimos, ainda, que as professoras assinalassem os motivos pelos quais haviam deixado de utilizar a(s) ferramenta(s). Uma delas informou que ainda não havia surgido a oportunidade; outra informou que não sentiu necessidade de usar a(s) ferramenta(s) com sua turma; três assinalaram a opção "outro motivo". As opções "a ferramenta não era adequada para as crianças da sua turma e/ou para o seu trabalho pedagógico" e "a oficina ministrada não ofereceu elementos suficientes para a utilização de forma segura" não foram assinaladas pelas professoras (Figura 2), o que corrobora a ideia de que a formação contemplou a utilização de recursos adequados ao trabalho com crianças da Educação Infantil, e as oficinas atenderam às expectativas do grupo de professoras, aspectos já informados por elas nos formulários de avaliação disponibilizados após cada oficina. 
Se você deixou de usar alguma(s) das ferramentas apresentadas nas oficinas, isso ocorreu porque: (pode assinalar mais de uma opção)

5 respostas

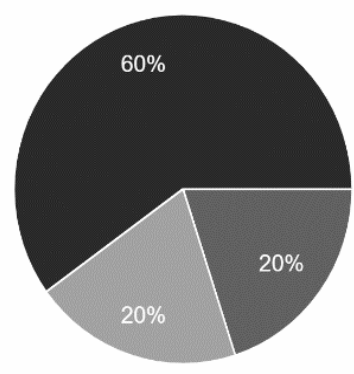

você não sentiu necessidade de utilizar $a(s)$ ferramenta(s)

a ferramenta não era adequada para as crianças da sua turma e/ou para o seu trabalho pedagógico

ainda não houve oportunidade

a oficina ministrada não ofereceu elementos suficientes para a utilização de forma segura

outro motivo

\section{Figura 2. Gráfico referente ao motivo da não utilização dos recursos tecnológicos apresentadas nas oficinas}

As professoras que marcaram "outro motivo" no gráfico da figura 2, justificaram: "como a oportunidade ficou longe da oficina, realmente eu não lembrava mais dos detalhes e acabei não utilizando como eu planejei utilizar o Google Sites"; "algumas crianças acessam pelo celular, então, a meu ver, ficaria uma proposta desigual de acesso a uma experiência"; "gestão do tempo para estudar mais a ferramenta e a experimentar".

Essa análise deixa claro que todas as professoras utilizaram o mínimo de duas e o máximo de quatro das ferramentas trabalhadas nas oficinas, a saber: as Professoras A e C usaram três (Google Drive, Google Forms e Google Meet); a Professora B usou duas (Google Drive e Google Meet); a Professora D usou quatro (Google Drive, Google Forms, Jamboard/Desenhos e Google Meet); a Professora E usou três (Google Drive, Jamboard/Desenhos e Google Meet). Dentre as ferramentas estudadas, somente o Google Sites não foi utilizado pelas professoras.

\section{Considerações Finais}

As oficinas mostraram-se relevantes para a utilização das TDIC como ferramentas de suporte ao processo de ensino e aprendizagem, vivenciado de forma remota durante a pandemia. As discussões sobre a formação continuada de professores para lidar com o mundo em transformação e inserir recursos digitais em sua prática pedagógica mostraram-se cada vez mais atuais, especialmente nesse contexto de isolamento social.

As oficinas foram propostas pelas professoras e, pelos dados coletados, atenderam às suas necessidades e interesses. Contudo, houve pouco tempo para a apropriação tecnológica em razão da urgência de sua utilização, dada a imperiosa necessidade do trabalho remoto. Ademais, a escolha dos recursos digitais para a Educação Infantil deve levar em conta as especificidades desse nível de ensino, em que o lúdico e as interações são fundamentais.

Outro aspecto a ser considerado na escolha das ferramentas é que as crianças da Educação Infantil ainda não leem nem escrevem convencionalmente, razão pela qual é necessário um mediador para auxiliá-las durante os encontros remotos, além de recursos interativos, que utilizam sons e imagens, de fácil navegação e com reconhecido valor pedagógico. 


\section{Referências Bibliográficas}

Brasil. (2018) "Base Nacional Comum Curricular: educação é a base". Ministério da Educação. Secretaria de Educação Básica. Secretaria de Educação Básica - Brasília: MEC, SEB.

Brasil. (2002) "Referenciais para Formação de Professores". Ministério da Educação. Secretaria de Educação Fundamental - Brasília: MEC, SEF.

Brasil. (2010) "Diretrizes Curriculares Nacionais para a Educação Infantil". Ministério da Educação. Secretaria de Educação Básica - Brasília: MEC, SEB.

Brasil. (2020) "Conselho Nacional de Educação". Resolução CNE/CP N 2, de 10 de dezembro de 2020. Disponível em: https://www.in.gov.br/en/web/dou/-/resolucao cne/cp-n-2-de-10-de-dezembro-de-2020-293526006. Acesso em: 20/07/2021.

Costa, D. e Lopes, J. (2016) "Quem Forma se Forma e Reforma ao Formar": uma discussão sobre as TICs na Formação de Professores. Tecnologia, Sociedade e Educação na Era Digital, Duque de Caxias, Rj, v. 1, p. 157-194.

Dias, C. R. S. D. et al. (2020) "Formação de professores da Educação Básica para uso das ferramentas Google na educação: uma experiência extensionista em tempos de pandemia". In: Anais do XXVI Workshop de Informática na Escola.

Hitzschky, R. A. et al. (2018) "A utilização de recursos educacionais digitais no ambiente escolar: da formação continuada à vivência tecnológica". In: Anais do XXIV Workshop de Informática na Escola

Hitzschky, R. A. et al. (2020) "A utilização de recursos educacionais digitais no ambiente escolar: da formação continuada à vivência tecnológica". In: V Congresso sobre Tecnologias na Educação

Kenski, V. M. (2007) "Educação e tecnologias: o novo ritmo da informação". Campinas, São Paulo, Papirus.

Santos, A. e Teixeira, A. C. (2019) "A Formação de Professores e a importância da Fluência Tecnológica Digital em meio ao cenário do Século XXI”. In: Anais do XXV Workshop de Informática na Escola. 